EESTI NSV TEADUSTE AKADEEMIA TOIMETISED. IX KOIDE

FOOSIKALIS-MATEMAATILISTE JA TEHNILISTE TEADUSTE SEERIA, 1960, NR. 4

ИЗВЕСТИЯ АКАДЕМИИ НАУК ЭСТОНСКОЙ ССР. ТОМ IX

СЕРИЯ ФИЗИКО-МАТЕМАТИЧЕСКИХ И ТЕХНИЧЕСКИХ НАУК. 1960, № 4

\title{
О РАЗНЫХ ПУТЯХ РАЗВИТИЯ НАУТИЛОИДЕЙ
}

\section{Х. СТУМБУР}

Изучение индивидуального развития животных имеет большое значение при выяснении их крупных таксономических групп. В. Н. Шиманский, изучавший онтогенез цефалопод, пришел к выводу, что все внешнераковинные головоногие можно раздедить на имеющих личиночную стадию - Larvat a (Ammonoidea и Bactritoidea) и не имеющих этой стадии развития - Alarvata (все наутилоидеи в широком смысле) ([16], стр. 99). По нашему мнению, предложение В. Н. Шиманского дает основу для дальнейшего исследования развития цефалопод и для выделения крупных систематических единиц как для наутилондей, так и для аммоноидей.

В настоящей статье в основу анализа разных путей развития цефалопод положено изменение высоты воздушных камер и положения сифона на ранних стадиях их развития. Высота воздушных камер должна отражать взаимоотношения между скоростью роста раковины и возникновением перегородок, характерные для данного вида, хотя в какой-то степени она зависит и от индивидуальных особенностей животного и от влияния среды. Таким образом, по данным измерения высоты камер можно проанализовать ход роста раковины, возникновение перегородок и их онтогенетические особенности. Изменения в положении сифона связаны с изменениями строения заднего конца мягкого тела.

Для удобства анализа автор составил графики, где на оси ординат отложена высота воздушных камер (в миллиметрах), а на оси абсцисс - их порядковые номера. На других графиках отражено положение сифона, выраженное через отношение расстояния сифона от вентральной стороны к диаметру раковины или оборота. Такое определение показывает положение сифона независимо от его удаления от стенки раковины, которое происходит в связи с расширением оборота или с увеличением диаметра снфона. На этих графиках на оси ординат откладывались значения вычисленных отношеннй, а на оси абсцисс - порядковые номера воздушных камер.

В работе использованы как каменный материал из Геологического музея АН әССР н из коллекций В. Н. Шиманского и М. Ф. Богословской, так и литературные данные $[1,3,4,5,8,9,11,12,15,20,23]$. Всего составлено 63 кривых высот воздушных камер и положения сифона, из которых в статье приведены только некоторые кривые для разных видов наутилоидей и аммоноидей (фиг. 1 и 2).

Остановимся, прежде всего, на кратком описании развития аммоноидей, так как их онтогенез хорошо изучен, что дает возможность при описании развития наутилоидей сравнивать их с аммонондеями.

Ранние стадии развития аммоноидей изучены Карпинским, Хайэттом, Шульга-Нестеренко [18], Смитом [23], Бодылевским [7], Шиндевольфом $\left[{ }^{21,22}\right]$, Богословской $\left.{ }^{6}\right]$ и др. Результаты этого изучения показали, что в период внутрияйцевого развития у аммоноидей образуются только первая субсферическая воздушная камера и жилая камера. 
Смит [23] предполагает, что протоконх и жилая камера до первого пережима не являются всей эмбориональной раковиной, так как после выхода из яйца задняя часть личинки находится еще в протоконхе и по мере вытягивания ее из протоконха подрастает и жилая камера. В протоконхе отстаются только просифон и кончик задней части тела - цекум. После этого рост раковины прекращается и животное переживает длительный период покоя, который отмечается на раковине пережимом, соответствующим личиночной стадии. В течение этого периода животное должно было достигнуть такой степени зрелости, чтобы стать настоящим аммонитом, начать выделять перегородки и строить нормальный сифон. Конещ личиночной стадии определяется образованием первой перегородки $\left[{ }^{23,18}\right]$. Остальные стадии развития выделяются на основе развития и усложнения перегородок.

Но существуют и другие мнения, по которым личиночная стадия развития продолжается до появления первых признаков, характерных для семейства, к которому данный вид принадлежит [10].

Интересные данные приводятся в работе Бодылевского [7], посвященной описанию онтогенетического развития Cadoceras elatmae Nik. При описании скульптуры раковины автор отмечает, что поверхность раковины до пережима совсем гладкая и только после пережима появляются слабо волнистые штрихи роста, которые постепенно возрастают и при диаметре диска около 8 мм образуют на боковой и наружной поверхностях оборота хорошо выраженные ребра. При диаметре 3,5 9 мм наблюдаются последние изменения в строении перегородочной линии. Далее новых элементов не появляется. Поперечник оборота раковины Cadoceras elatmae Nik. превышает ее высоту на протяжении около трех оборотов (до диаметра 8-10 мм), когда сечение приобретает очертание почти круга. Далее происходит постепенное приобретение очертания, характерного для возрослого индивида.

Очень интересные данные об изменении положения сифона на ранних стадиях развития аммоноидей приводит Шульга-Нестеренко. Она отмечает $\left(\left[{ }^{18}\right]\right.$, стр. 88-89), что у большинства мезозойских аммонитов сифон проходит на протяжении первых оборотов через центр перегородок и затем постепенно переходит на их брюшную сторону, а у большинства верхнепалеозойских аммоноидей, изученных М. И. ШульгаНестеренко, А. П. Карпинским и М. Ф. Богословской (Parapronorites, Medlicottia, Gastrioceras, Adrianites, Stacheoceras, Pronorites, Episageceras, Prolecanites, Goniatites, Glyphioceras, Artinskia, Sakmarites, Crimites и др.), сифон принимал вентральное положение сразу же после выхода животного из яйца. Только у одного вида Agathiceras uralicum Karp. (из материала М. И. Шульга-Нестеренко) сифон имел центральное положение, а на четвертом обороте получил вентральное положение. Опираясь на вышеприведенный материал, М. И. Шульга-Нестеренко пришла к выводу, что палеозойские аммониты происходят от общих с мезозойскими аммонитами предков, которые, вероятно, существовали в силуре. В связи с ускорением развития положения сифона у палеозойских аммонитов выпала стадия срединного положения сифона и в их молодых оборотах воспроизведено положение сифона, характерное для взрослой стадии.

Изменения величины жилой камеры личиночной стадии аммоноидей (до первого пережима), изученные Гранжаном $\left[{ }^{19}\right]$ и Шульга-Нестеренко $\left[{ }^{18}\right]$, показывают, что жилая камера личинки мезозойских форм имела длину, равную примерно $3 / 4$ оборота (например, у Hildoceras bifrons величина жилой камеры личинки равняется $270^{\circ}$ ), а у палеозойских 
форм она равна почти целому обороту или даже превышает его (например, у Adriänites globosus - 365). Учитывая филогенетические связи. между мезозойскими и палеозойскими аммоноидеями, установленные М. И. Шульга-Нестеренко, на основе изменения положения сифона можно сделать вывод, что в процессе эволюции длина их жилой камеры увеличилась.

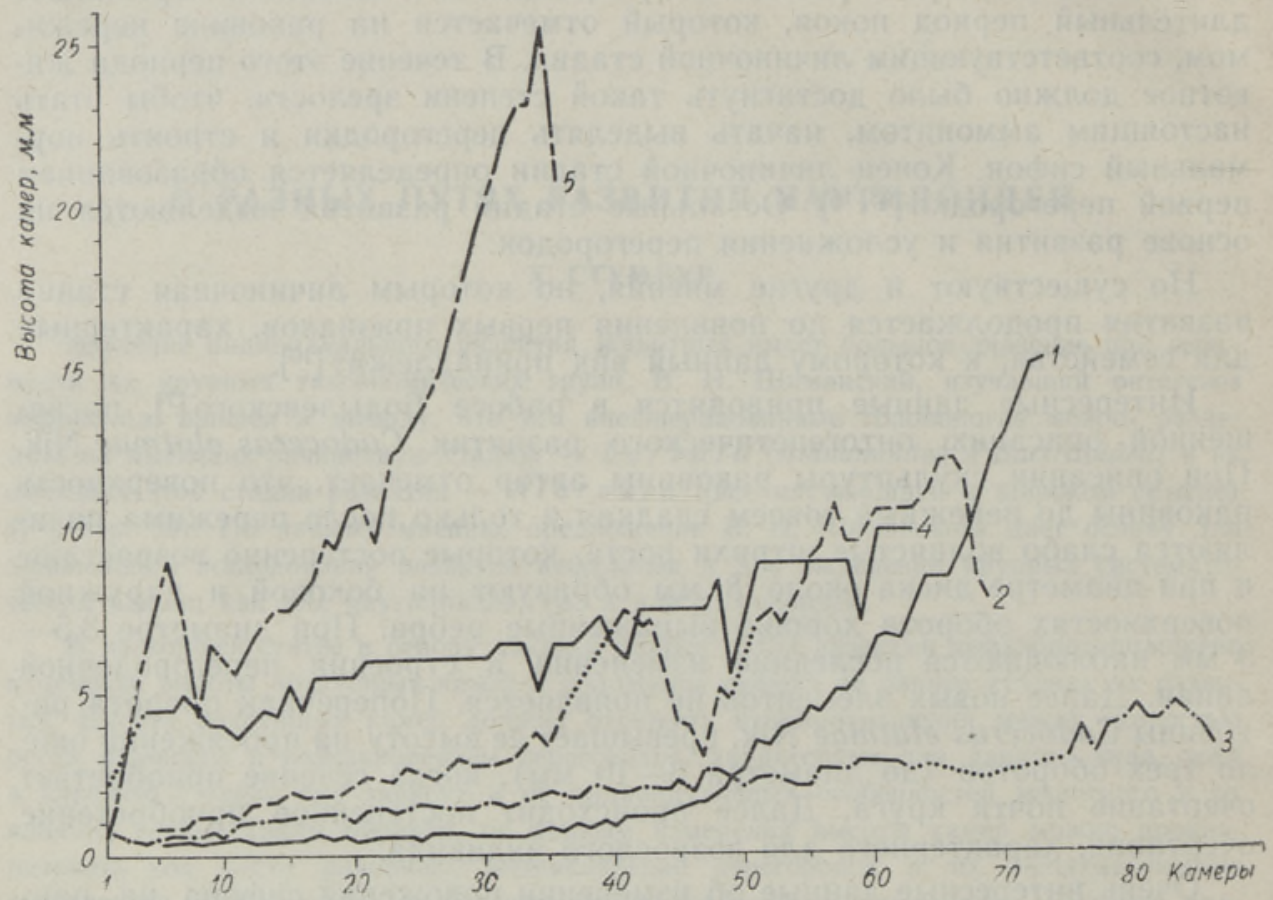

Фиг. 1. Кривые изменения высоты воздушных камер: 1 - Craspedodiscus phillipsi (Neum.), C 1276; Ульяновск; $\mathrm{Cr}_{1} .2$ - Lituites sp., C 1259-61 и 1277; северо-восточная Эстония; средний ордовик, ласнамягиский горизонт $\left(\mathrm{C}_{\mathrm{I}} \mathrm{b}\right) .3-$ Trocholites depressus (Eichw.), С 1299; Пальдиски, северная Эстония; средний ордовик, ласнамягиский горизонт $\left(\mathrm{C}_{\mathrm{I}}\right.$ b).4-Estonioceras sp., C 1273; Валькла, северная Эстония; нижний ордовик, кундаский горизонт ( $\left.\mathrm{B}_{\mathrm{III}}\right)$. 5-Nautilus pompilius L., C 1272.

Кривые высоты воздушных камер удалось составить для пяти представителей аммоноидей: Platyclymenia sp. $\left(\mathrm{D}_{3}\right)$, Lytoceras lineatum Schl. $\left(\mathrm{J}_{1}\right)$, Leioceras opalinum (Reinecke) $\left(\mathrm{J}_{2}\right)$, Craspedodiscus phillipsi (Neum.) ( $\left.\mathrm{Cr}_{1}\right)$ и Deshayesites deshayesi Leum. $\left(\mathrm{Cr}_{1}\right)$ (фиг. 1). На рисунке приведена кривая высоты воздушных камер (кривая 1) Craspedodiscus phillipsi (Neum.), поскольку она оказалась наиболее характерной для этой группы головоногих. Ниже приводится описание развития этого вида.

\section{Craspedodiscus phillipsi (Neum.)}

Апикальный конец и жилая камера не сохранились, в связи с чем кривая не совсем полная (фиг. 1,1$)$. Высота воздушных камер сначала, от пятой до 43-й камеры, увеличивается медленно (всего с 0,4 до 1,2 мм!), однако затем увеличение высоты происходит очень быстро (от 
1,2 до 15,2 мм). Рост происходит весьма равномерно, но между 50-ӥ и 65-й камерами равномерность его нарушается и увеличение высоты чередуется с уменьшением. Септы в апикальной части (2,5 оборота) почти прямо-поперечные. Начиная от 26-й камеры септы постепенно изгибаются вперед и от 50-й уже сильно выпуклые. В этой же области пронсходит утолщение их центральной части, а от 61-й камеры последняя начннает изгибаться назад. Далее характер септ не меняется. Изменения внутреннего строения и медленное увеличение высоты камер происходят на протяжении примерно 5 оборотов, которые имеют диа. метр диска 8,5 мм.

y других изученных аммонитов на границе медленного и быстрого увеличения высоты воздушных камер наблюдаются и изменения во внутреннем строении и в скульптуре раковины. Так, у Lytoceras lineatum и Leioceras opalinum в этом месте (у 3-го оборота) наблюдаются изменения в скульптуре -- гладкая раковина покрывается хорошо выраженными ребрами - и в характере септ. У артинских аммоноидей в пределах 3-5-го оборотов наблюдаются изменения в строении сифона: сифонные дудки, до сих пор направленные назад, направлены теперь вперед (например, у Uraloceras fedorovi (Karp.), U. suessi (Karp.). Waagenia subinterrupta (Krot.) и у Thalassoceras gemmellaroi Кагр.; см. $\left.{ }^{6}\right]$, стр. $55-57$ ).

На основании анализа изученного материала в развитии аммонондей можно выделить две стадии, характеризующиеся различными скоростямн роста высоты воздушных камер. Первая стадия (у Craspedodiscus phillipsi до 50-й камеры) характеризуется незначительной скоростью роста и коренными изменениями внутреннего строения раковины, вторая стадия - большой скоростью роста.

В последнее время исследователи стали уделять больше внимания изучению ранних стадий развития наутилоидей. Так, ранние стадии развития спиральных наутилоидей изучались Вилли [ $\left.{ }^{25}\right]$, Шиманским [11, 15, 17], Руженцевым $\left[{ }^{11}\right]$, Балашовым $\left[{ }^{2}\right]$ и Стумбуром $\left[{ }^{12}\right]$. Әти исследования показали, что свернутые наутилоидеи в эмбриональной стадии не имели протоконха. В течение эмб́рионального развития у них образовывалась многокамерная эмбриональная раковина, и из яйца выходил вполне сформировавшийся молодой индивид. Их внутрияйцевое развитие можно подразделить на три этапа. На первом этапе (этап первичного колпачка) их внутреннее строение и внешняя форма раковины обладают строением предка; на втором (этап внутренних изменений в строении раковины) происходит окончательное формирование внутреннего строения раковины (смещение сифона) и быстрый рост высоты камер, а на третьем (этап формирования внешней формы раковины) формируется внешняя форма раковины и продолжается рост высоты камер. После выхода из яйцевых оболочек происходит резкое снижение высоты воздушных камер, связанное с задержкой в росте раковнны, и начинается образование скульптуры и поперечного сечения, характерных для взрослой раковины $\left[{ }^{12}\right]$. Интересные данные об изменении положения сифона выясняются при сравнении верхнепалеозойских свернутых наутилоидей с нижнепалеозойскими. У первых (Metacoceras, Heurekoceras, Articheilus, Parastenopoceras, Aktubonautilus, Pararhiphaeoceras, Sholakoceras, Neothrinoceras, Condraoceras) сифон имеет во взрослых оборотах субвентральное или центральное положение, у вторых (Curtoceras, Schroederoceras, Discoceras и др.) в большинстве случаев - субдорсальное нли дорсальное. Субвентральное положение сифона имеют только Estonioceras, Planctoceras и Tarphyceras. Изучение ранних стадий развития раковины с дорсальным положением сифона показывает, 
что эти формы происходят из наутилоидей, у которых сифон имеет брюшное положение, так как на их ранних стадиях сифон находится в вентральном положении. Как у верхнепалеозойских, так и у нижнепалеозойских наутилондей в процессе эволюции намечается увеличение эмбриональных раковин. У низших форм она состоит из половины оборота, а у высших - из 11/4 оборота (Discoceras). Соответственно увеличнвались и размеры яйц.

Хорошо изучены ранние стадии развития верхнепалеозойских прямых наутилоидей $\left[{ }^{13,15}\right]$, у которых можно выделить три типа эмо́риональных раковин. K первому типу относятся раковины с колпачкообразной первой камерой, прямые и островершинные (Dolorthoceras stiliforme Shim. и D. siphocentrale (Krotow), ко второму - согнутые, островершинные и с колпачкообразной первой камерой (Pseudorthoceras knoxense (Mc Chesney), P. neumannae Shimansky, Uralorthoceras tzwetaëvae Shimansky, U.verneuili) (Möller), к третьему - прямые, булавовидные со сферической первой камерой (Shikhanoceras sphaerophorum Shimansky).

Слабее изучены ранние стадии развития нижнепалеозойских прямых и согнутых наутилоидей. Из последних исследований по прямым и согнутым наутилоидеям можно назвать только работы Журавлевой [8,9] и Балашова $\left[{ }^{3,4}\right]$. Исследования Ф. А. Журавлевой показывают, что у лрямых и согнутых наутилоидей в период внутрияйцевого развития образуется обычно от одной до трех воздушных и жилая камера [9]. Крайне своеобразно проходило развитие прямых широкосифонных и эндоцероидных наутилоидей, у которых из яйцевой капсулы должна была выходить крупная особь с весьма снльно развитым сифоном, заполнявшим почти всю первую камеру.

Для наутилоидей удалось начертить 58 кривых высоты воздушных камер и расположения сифона. Ниже рассматривается развитие четырех представителей полусвернутых (Lituites sp. $\left(\mathrm{O}_{2}\right)$ ) и свернутых наутилоидей (Trocholites depressus (Eichw.) $\left(\mathrm{O}_{2}\right)$; Estonioceras sp. $\left(\mathrm{O}_{1}\right)$ и Nautilus pompilius L.).

\section{Lituites sp.}

Кривая высоты воздушных камер последнего составлена на базе нескольких экземпляров (фиг. 1, 2). Высота воздушных камер в спиральной части раковины увеличивается очень медленно (от пятой до 35-й камеры только на 2,5 мм). От места, где раковина развертывается, высота камер резко возрастает и достигает у 41 -й камеры 7,3 мм, а в том месте, где раковина выпрямляется, наблюдается резкое уменьшение высоты (от 43-й и до 47-й камеры на 4,4 мм). Уменьшение высоты происходит и у основания жилой камеры (с 12 до 7,5 мм).

Первая камера изученных нами экземпляров не сохранилась. В работе Шиндевольфа [22] приведен рисунок апикального конца Lituites perfectus Wahl., где видна первая слабо обособленная камера. Сифон в ней расположен вентрально. В следующих очень низких камерах он отходит от вентральной стороны и, начиная примерно с девятой камеры, занимает центродорсальное положение.

Спиральная часть раковины состоит из $3 \frac{1}{2}$ оборотов и покрыта прямо-поперечными ребрами. Поверхность ортокона тоже покрыта ребрами, но здесь они образуют пять синусов и седел. Сифон имеет в спиральной части раковины центродорсальное положение. В месте развертывания раковины сифон отходит от дорсальной стороны ближе к 
центру, но в старческой стадии снова приближается к дорсальной стороне (фиг. 2,1$)$.

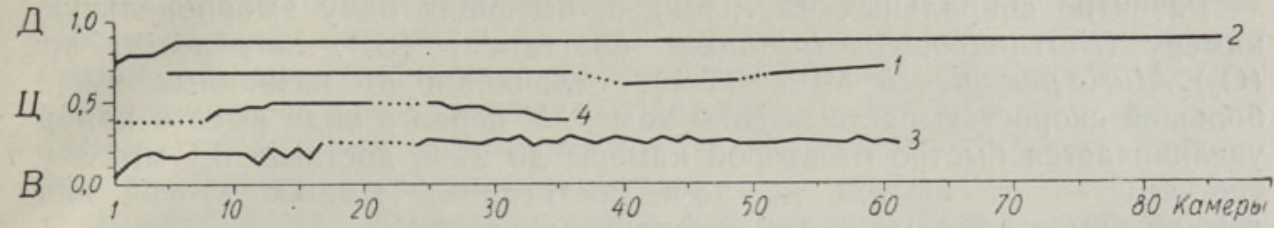

Фиг. 2. Кривые изменения положения сифона: $B$ - вентральное, Ц - центральное и Д - дорсальное. 1 - Lituites sp. С 1259-61 и 1277; северо-восточная Эстония; средннй ордовик, ласнамягиский горизонт $\left(\mathrm{C}_{\mathrm{I}} \mathrm{b}\right) .2$ - Trocholites depressus (Eichw.), С 1299 , Пальдиски, северная Эстония, средний ордовик, ласнамягиский горизонт $\left(\mathrm{C}_{\mathrm{I}} \mathrm{b}\right)$. 3 - Estonioceras sp., С 1273; Валькла, северная Эстония; нижний ордовик, кундаский горизонт $\left(\mathrm{B}_{\mathrm{mII}}\right) .4$ - Nautilus pompilius L., C 1272.

У этого представителя наутилоидей в период внутрияйцевого развития образуется только одна камера. Медленное увеличение высоты камер в спиральной части раковины и быстрое увеличение в ортоконе очень сильно напоминает процесс роста высоты воздушных камер аммоноидей (Platyclymenia sp., Lytoceras lineatum Schl.). Возможно, что развитие Lituites проходило несколько стадий, а на границе этих стадий происходило замедление роста в связи с перестройкой мягкого тела и раковины.

Подобным образом развиваются также Ancistroceras torelli Remelé и A. undulatum Boll., но на границе спиральной части раковины и ортокона у них не происходит столь резкого уменьшения высоты камер, как y Lituites sp.

\section{Trocholites depressus (Eichw.)}

Высота воздушных камер в начале уменьшается (высота первой составляет 0,8 , а четвертой - 0,4 мм). Начиная от четвертой камеры высота медленно увеличивается до 75 -й (с 0,4 до 2,8 мм). Далее высота увеличивается быстрее и достигает у 83-й камеры 4,5 мм. Перед жилой камерой наблюдается сильное уменьшение высоты камер до 3,2 мм $(ф и г . ~ 1,3)$. Первая камера относительно высока и имеет асимметричную форму. Пупковое отверстие очень маленькое (ширина 0,03 и длина 0,1 мм). Сифон в первой камере расположен субдорсально, а в следующих камерах он приближается к дорсальной стороне и уже в шестой занимает дорсальное положение (фиг, 2, 2). Скульптура сохранилась только у экземпляра № 1262, состоящего из четырех оборотов. Обороты раковины покрыты прямо-поперечными ребрами (только латеральные стороны) и штрихами роста. Скульптура последнего оборота, к сожалению, не сохранилась.

В период внутрияйцевого развития, очевидно, образовывалась только первая камера, высота которой отличается от последующих. Развитие раковины Trocholites depressus сильно напоминает развитие аммонондей (почти точно такую же кривую имеет Deshayesites deshayesi(Leym.)), но отличается от них по форме первой камеры.

Аналогично развиваются Lyecoceras gotlandense Mutvei и приведенные в статье Ф. А. Журавлевой прямые и согнутые наутилоидеи ([9], табл. 1; Geisonoceras sp. 1, G. sp. 2, Phragmoceras timanicum Holzapfel, Paracleistoceras sp., Anglicornus sp. 2, Turoceras schnyrevae Zhuravleva 
и др.), у которых в период внутрияйцевого развития также образуется одна (или до трех) симметричная или асимметричная камера.

Развитие спиральных наутилоидей, имеющих одну эмбриональную камеру (Barrandeoceras tyrannum (Barrande) $\left(\mathrm{S}_{2}\right)$, Tarphyceras sp. $\left(\mathrm{O}_{2}\right)$, Aturia panamensis Miller $\left.(\mathrm{Tr})\right)$, отличается от названных выше большей скоростью роста высоты камер. У первого вида высота камер увеличивается быстро от второй камеры до 24-й, достигая 6,1 мм, а у третьего - от шестой до 23-й, достигая 8,0 мм. Со второй или шестой камеры кривые круто поворачивают вверх.

Подобным же образом развиваются Orthoceras, Shikhanoceras sphaerophorum Shimansky, у которых первая камера четко обособлена.

\section{Estonioceras sp.}

Кривая высот воздушных камер вначале поднимается очень быстро. Увеличение происходит до седьмой камеры, высота которой достигает 5 мм. После седьмой камеры высота уменьшается до 3,5 мм, а затем снова увеличивается и достигает в 21-й камере 6 мм. Далее рост раковины происходит неравномерно (рис. 1,4).

В период эмбрионального развития образуется, по-видимому, семь камер, в пределах которых происходит почти полное формирование внутреннего строения взрослой раковины [12]. После выхода животного из яйца происходят еще незначительные изменения в положении сифона (до 17-й камеры; рис. 2, 3) и образуется скульптура взрослой раковины. В этой части кривой (от седьмой до 17-й камеры) наблюдаемое снижение высоты камер связано, очевидно, с выходом молодого индивида из яйца, а неравномерное увеличение высоты камер обусловлено отмеченными выше последними изменениями в строении раковины и мягкого тела. Далее в строении раковины никаких изменений не наблюдается.

Такие же кривые, отличающиеся только по высоте, получены для Schroederoceras sp. $\left(\mathrm{O}_{3}\right)$, Curtoceras teres (Eichw.) $\left(\mathrm{O}_{2}\right)$, Estonioceras imperfectum Quend. $\left(\mathrm{O}_{1}\right)$ и Discoceras antiquissimum (Eichw.) $\left(\mathrm{O}_{3}\right)$. Аналогичные кривые получены и для верхнепалеозойских свернутых наутилоидей (Articheilus luxuriosum Ruzh. et Shim., Aktubonautilus eruciformis Ruzh. et Shim., Metacoseras orthogonium Ruzh. et Shim., Rhiphaeoceras humile Ruzh. et Shim., Neothrinoceras soshkinae Ruzh. et Shim., Metacoceras parartiense Ruzh. et Shim. и др.), а также для прямых наутилоидей, имеющих несколько эмбриональных камер (Dolorthoceras stiliforme Shim., Uralorthoceras tzwetaëvae Shim. и др.).

\section{Nautilus pompilius $\mathrm{L}$.}

Высота камер вначале очень быстро увеличивается, достигая у шестой камеры 9,2 мм. Затем высота сильно уменьшается (до 4,5 мм), а далее снова увеличнвается. Сначала увеличение происходит неравномерно, чередуясь с уменьшениями, но после 23-й протекает очень быстро и достаточно равномерно. После 23-й камеры высота увеличивается с 12,2 до 25,5 мм, а у основания жилой камеры вновь уменьшается до 4,5 мм (фиг. 1,5 ).

Сифон в первой камере расположен субцентрально (ближе к вентральной стороне). В следующих камерах он сдвигается ближе к центру 
и в девятой камере занимает уже центральное положение, а в старческой стадии снова слегка сдвигается к вентральной стороне (рис. 2, 4).

В эмбриональной стадии образуются первые самые высокие камеры. После выхода животного из яйца высота нескольких первых камер сильно уменьшается, а рост раковины еще в течение весьма длительного периода сильно замедлен и неравномерен, что обусловлено, по-видимому, последними изменениями в строении мягкого тела. Позднее рост раковины происходит равномерно.

Кривая высоты воздушных камер Nautilus pompilius L. в общих чертах не отличается от кривых палеозойских свернутых наутилоидей, но они очень отчетливо отличаются по относительной скорости роста. Таким же путем, как Nautilus pompilius, развивается и Cymatoceras $\left(\mathrm{Cr}_{1}\right)$.

Из вышеизложенного материала видно, что у аммоноидей существует после эмбриональной и личиночной стадии развития еще длительный период, в течение которого они переживают коренные изменения во внутреннем строении, во внешней форме и скульптуре раковины и в строении лопастных линий. Этот период характеризуется образованием низких воздушных камер, составляющих до 5 оборотов (диаметром до 10 мм).

У наутилоидей (Lituites sp., Trocholites depressus и др.), у которых в период внутрияйцевого развития образуется одна воздушная камера, так же как и у аммоноидей существует после эмбриональной стадии развития достаточно длительный период, в течение которого они переживают довольно глубокие изменения во внутреннем строении, во внешней форме и в скульптуре. В этот период образуются низкие камеры, составляющие от 3 до 5 оборотов. Судя по характеру кривых высоты воздушных камер и по изменениям строения раковины, развитие представителей этой группы происходит очень похоже на развитие аммоноидей, но изученный материал не дал возможности для решения вопроса о существовании у названных наутилоидей личиночной стадии. Интересно отметить, что в этой группе встречаются и такие формы, у которых первая камера имеет полусферическую и сильно обособленную форму (Orthoceras, Shikhanoceras, Bactroceras, Lituites perfectus) и такие, у которых в период внутрияйцевого развития образуются, возможно, две или три воздушных камеры, хотя высота второй или третьей камеры лишь равна высоте первой камеры или немного меньше ([9], рис. 1 Geisonoceras sp. No. 2, Turoceras schnyrevae, Phragmoceras timanicum).

У прямых и свернутых наутилондей (Estonioceras sp., Nautilus pompilius, Cymatoceras sp. и др.), у которых в период внутрияйцевого развития образуется четыре или больше камер, после выхода животного из яйца не замечается существенных изменений ни во внутреннем строении, ни во внешней форме раковины.

Развитие первой группы наутилоидей происходит подобно аммоноидеям, хотя у большинства из них первая камера необособлена. Развитие второй группы наутилоидей отличается от развития аммоноидей и первой группы наутилоидей, но первая и вторая группы наутилоидей связаны между собой внешней формой первой камеры. Основное различие между выделяемыми группами состоит, по-видимому, в том, что у первой группы в яйце не обеспечивается полное завершение зародышевого развития и из яйца выходит неполностыю развитая личинкообразная особь, которая продолжает развиваться после выхода из яйца на протяжении до 75 камер, а у второй группы уже в яйце обеспечивается полное завершение эмбрионального развития и из яйца выходит полностью сформировавшийся молодой индивид. 
На базе материала, имеющегося в распоряжении автора, и литературных данных удалось наметить два основных пути развития наутилоидей, но сделать окончательные выводы о распространении одного и другого типов развития в разных систематических группах, конечно, оказалось невозможно. Все же ясно, что изучение разных путей развития и эмбриональных стадий весьма важно для выяснения особенностей таких групп, как аммоноидеи и наутилоидеи, и послужит основой для составления естественной системы головоногих.

\section{ЛИТЕР А Т Р А}

1. 3. Г. Бал аш ов, Свернутые и полусвернутые наутилоидеи ордовика Прибалтики, Тр. ВНИГРИ, вып. 78, 1953.

2. 3. Г. Ба л а шов, К вопросу о развитии начальных камер у наутилондей, Вестн. Ленингр. ун-та. Сер. биол., № 10, 1953.

3. 3. Г. Б а л а шо в, Протоконх древнепалеозойского представителя рода Orthoceras. Докл. АН СССР, т. 116, № 5, 1957.

4. 3. Г. Ба л ашов, Начальные камеры актиноцероидных наутилондей. Вестн. Ленингр. ун-та. Сер.. геол. и геогр., вып. 3, № 18, 1958.

5. Б. И. Богословски й, Девонские аммоноидеи Рудного Алтая, Тр. Палеонтол. ин-та АH CCCP, т. LXIV, 1958.

6. М. Ф. Богословская, Внутреннее строение раковины некоторых артинских аммоноидей, Палеонтол. ж., № 1, 1959.

7. В. И. Бод ылевский, Развитие Cadoceras Elatmae Nik., Ежеr. Русск. палеонтол. о-ва, т. 5 , ч. $1-2,1925$.

8. Ф. А. Жура влев а, О находках эмбриональных раковин прямых наутилоидей в силуре р. Курейки. (Автореферат доклада), Бюл. МОИП, Отд. геол., т. ХХХ, вып. 1, 1955.

9. Ф. А. Ж ур а в лев а, Об эмбриональных стадиях развития наутилоидей. Палеонтол. ж., № $1,1959$.

10. В. Е. Ру женце в, Опыт естественной систематики некоторых верхнепалеозойских аммонитов. Тр. Палеонтол. ин-та АН СССР, т. ХІ, 1940.

11. В. Е. Руженцев и В. Н. Ш и м ан ски й, Нижнепермские свернутые и согнутые наутилоидеи Южного Урала. Тр. Палеонтол. ин-та АН CССР, т. L, 1954.

12. Х. А. С тумбур, Об эмбриональных раковинах некоторых ордовикских Tarphyceratida. Палеонтол. ж., № 2, 1959.

13. В. Н. Ш и м ан ск и й, $\mathrm{K}$ вопросу о ранних стадиях развития верхнепалеозойских ортоцераконовых наутилоидей, Докл. АН СССР, т. LX, № 5, 1948.

14. В. Н. Ш и м а с к й, Современный наутилус и его значение для изучения ископаемых головоногих, Уч. зап, МГПИ им. В. И. Ленина, Қафедра геологин, т. LII, вып. 3, 1948.

15. В. Н. Ш и м ански й, Прямые наутилоидеи и бактеритоидеи сакмарского н артинского ярусов Южного Урала, Тр. Палеонтол. ин-та АН CCCP, т. XLIV, 1954.

16. В. Н. Ши м а н ски й, О принципах выделения наиболее крупных систематическнх групп у цефалопод (Автореферат доклада), Бюл. МОИП, Отд. геол., т. ХХІХ, вып. 5, 1954.

17. В. Н. Ш и м а ски й, Систематика и филогения отряда Nautilida, Бюл. МОИП, Отд. геол., т. XXXII, вып. 4, 1957.

18. М. И. Шульга-Нестеренко, Внутреннее строение раковины артинских аммонитов, Бюл. МОИП, Отд. геол., т. IV, № $1-2,1926$.

19. F. G r a n j e a n, Le siphon des Ammonites et des Bélemnites, Bull. Soc. Géol. France, 4e Sér., t. II, 1910.

20. H. Mutvei, On the relations of the principal muscles to the shell in Nautilus and some fossil nautiloids. With a taxonomic appendix, Arkiv mineralogi och Geol., B. 2, nr. 10, 1957 .

21. O. H. Schindew olf, Zur Stammesgeschichte der Ammoneen, Paleont. Ztschr., Rd. 14, H. 3, 1932.

22. O. H. S chindew olf, Vergleichende Morphologie und Phylogenie der Aniangskammern tetrabranchiater Cephalopoden, Abhandl. Preuss. Geol, Landesanst. Neue Folge, H. 148, 1933. 
23. Perrin Smith, The Development of Glyphioceras and the Phylogeny of the Glyphioceratidae, Calif. Acad. Sci., Proc. Geology, Vol. I, No. 3, 1897.

24. W. Sweet, The Middle Ordovician of the Oslo Region, Norway, 10, Nautiloid Cephalopods, Norsk geol. tidsskr., bd. 38, h. 1, 1958.

25. A. Willey, The embryology of the Nautilus, Nature, Vol. 55, No. 1426, 1897.

Ннститут геологии

Академии наук Эстонской ССР
Поступила в редакцию

24. III 1960

\section{NAUTILOIDIDE ERINEVATEST ARENGUTEEDEST}

\section{H. Stumbur}

\section{Resümee}

Autor asub seisukohale, et väliskojaliste jagamine Siman§ki poolt kahte suurde rühma $\left[{ }^{16}\right]$, milledest esimest iseloomustab larvaalse staadiumi esinemine ontogeneesi varajasel perioodil (Larvata) ja teist - larvaalse staadiumi puudumine (Alarvata), annab ōige suuna peajalgsete fülogeneesi uurimisele ja head alused ammoniitide ning nautiloidide suurte taksonoomiliste rühmade väljaselgitamiseks ühistel alustel.

Peajalgsete arenguteede väljaselgitamiseks on käesoleva artikli autor muude tunnuste kōrval arvestanud gaasikambrite kōrgust ja sifooni asendi muutust ontogeneesi varajastes staadiumides. Joonisel 1 esitatakse gaasikambrite kōrgus millimeetrites. Joonis 2 kujutab sifooni asendi muutusi; sifooni asend väljendatakse keerme kōrguse ja sifooni kauguse (arvestades ventraalsest küljest) suhtena. Oldse koostati gaasikambrite kõrguse ja sifooni asendi muutuste kohta 63 kõverat. Neist tuuakse käesolevas artiklis viis kōige iseloomustavamat ammoniitide ja nautiloidide esindajate kohta.

Joonistelt on näha, et ammoniitidel esineb pärast vastsestaadiumi pikk periood, mille vältel kujunevad väga madalad gaasikambrid; need moodustavad kuni 5 keeret, diameetriga kuni $10 \mathrm{~mm}$. Seda perioodi iseloomustavad pōhjalikud muutused koja sise- ja välisehituses. Pärast vastsestaadiumi möödumist kasvab gaasikambrite kōrgus kiiresti (vt. Craspedodiscus phillipsi (Neum.), joon. 1 kōver 1 ; Platyclymenia sp. $\left(\mathrm{D}_{3}\right)$, Lytoceras lineatum Schl. $\left(\mathrm{J}_{1}\right)$, Leinceras opalinum (Reinecke) $\left(\mathrm{J}_{2}\right)$ jt.).

Alamatel nautiloididel (Lituites sp. $\left(\mathrm{O}_{2}\right)$, Trocholites depressus (Eichw.) $\left(\mathrm{O}_{2}\right)$ jt.), kelledel embrüonaalses staadiumis moodustub vaid üks gaasikamber, esineb, nagu ammoniitidelgi, pärast embrüonaalset staadiumi küllalt pikk periood, mille vältel kujunevad madalad gaasikambrid (joon 1, kōverad 2, 3; joon 2, kōverad 1,2). Sellel perioodil toimuvad ka viimased koja väliskuju ja siseehituse muutused (vt. Lituites sp.). Autori käsutuses olev materjal ei lubanud aga kindlaks teha vastsestaadiumi esinemist. Huvitav on märkida, et vaadeldavas grupis vôib leida nii selliseid vorme, kelledel embrüonaalses arengus moodustus üks poolsfäärilise kujuga kamber (näit. Orthoceras, Shikhanoceras, Bactroceras, Lituites perfectus Wahl.), kuid ka niisuguseid, kelledel embrüonaalses arengus moodustus arvatavasti kaks vōi kolm gaasikambrit (Geisonoceras sp. 2 (S). Turoceras schnyrevae Zhuravleva $\left(\mathrm{S}_{2}-\mathrm{D}_{1}\right)$, Phragmoceras timanicum Holzapiel $\left(\mathrm{D}_{3}\right)$, Barrandeoceras tyrranum. (Barr.) $\left(\mathrm{S}_{2}\right)$, Tarphyceras sp. $\left(\mathrm{O}_{2}\right)$ jt.).

Sirgetel ja spiraalsetel nautiloididel (Dolorthoceras stiliforme Shim. $\left(\mathrm{P}_{1}\right)$, Uralorthoceras tzwetaëvae Shim. $\left(\mathrm{P}_{1}\right)$, Estonioceras imperfectum (Quenst.) $\left(\mathrm{O}_{1}\right)$, Curtoceras teres (Eichw.) $\left(\mathrm{O}_{2}\right)$, Discoceras antiquissimum (Eichw.) $\left(\mathrm{O}_{3}\right)$, Metacoceras orthoconicum Ruzh. et Shim. $\left(\mathrm{P}_{1}\right)$, Rhiphaeoceras humile Ruzh. et Shim. ( $\left.\mathrm{P}_{1}\right)$, Cymatoceras sp. $(\mathrm{Cr})$, Nautilus pompilius L. jt.), kelledel embrüonaalses arengus moodustus paljukambriline koda, ei ole peale munast väljumist märgata koja ehituses olulisi muutusi ja gaasikambrite kõrguse kasv saavutab kohe maksimaalse kiiruse.

Nagu eespool toodud andmetest nähtub, sarnaneb esimese grupi nautiloidide (Lituites, Trocholites jt.) areng ammoniitide omaga, kuigi enamik nautiloidide esindajaist ei oma subsfäärilist kambrit. Teise grupi nautiloidide areng (Estonioceras, Nautilus jt.) erineb nii ammoniitide kui ka esimese grupi nautiloidide arengust, kuigi mõlema nautiloidide grupi esindajate enamikul on esimese kambri väliskuju ühesugune. Pōhiline erinevus vaadeldavate gruppide arengus seisneb selles, et esimese grupi nautiloididel toimus munas ebatäielik loote arenemine ja munast koorus lōplikult văljakujunemata larvitaoline isend, kes jätkas arenemist veel kuni 70 -nda kambri moodustamiseni, aga teise rühma nautiloididel arenes loode munas välja juba täielikult ning munast koorus väljakujunenud noor indiviid. 


\section{VON DEN VERSCHIEDENEN ENTWICKLUNGSWEGEN DER NAUTILOIDEN}

\section{H. Stumbur}

\section{Zusammenjassung}

Der Verfasser vertıitt den Standpunkt, dass die von W. Schimanski $\left.{ }^{16}\right]$ vorgeschlagene Einteilung der ectocochlien Cephalopoden in zwei grosse Gruppen - wovon die erste (Larvata) durch das Vorhandensein eines larvalen Stadiums in der frühen Periode der Ontogenese, die zweite (Alarvata) aber durch das Fehlen eines solchen Stadiums gekennzeichnet wird - die Erforschung der Entwicklungsgeschichte der Cephalopoden in die richtigen Wege leitet und die Herausfindung grösserer taxonomischer Gruppen der Ammoniiten und Nautiloiden auf einer gemeinsamen Grundlage ermöglicht.

Bei der Feststellung der Entwicklungswege der Cephalopoden zieht der Verfasser neben anderen Kennzeichen auch die Höhe der Luftkammern und die Veränderungen der Lage des Siphos während der früheren Stadien der Ontogenese in Betracht. Die Messangaben über die Höhe der Luftkammern sind graphisch dargestellt (Fig. 1), wobei die Ordinatenachse die Höhe der Luftkammern in Millimetern, die Abszissenachse die Luftkammern trägt. Fig. 2 veranschaulicht die in der Lage des Siphos stattfindenden Veränderungen. Die Lage des Siphos wird bestimmt als ein Verhältnis der Windungshöhe zur Entfernung des Siphos von der ventralen Seite. Die Ordinatenachse trägt die berechneten Verhält. nisse, die Abszissenachse - die Luftkammern. Insgesamt sind 63 Kurven der Luftkammernhöhe und der Veränderungen der Sipholage zusammengestellt worden. Davon bringt der Artikel 5 Kurven, welche die Entwicklung der Ammoniiten und Nautiloiden am besten charakterisieren,

Die graphischen Darstellungen des Wachstums zeigen, das bei den Ammoniiten ausser dem Larvenstadium noch eine längere Periode auftritt, während deren sehr niedrige Luftkammern entstehen, die bis 5 Windungen von einem Durchmesser bis $10 \mathrm{~mm}$ bilden. In dieser Periode finden bedeutende Veränderungen des inneren Aufbaus und der äusseren Form des Gehäuses statt. Darauf beginnt ein schnelles Wachstum der Höhe der Luftkammern (Craspedodiscus phillipsi (Neum.) (Fig. 1, Kurve 1), Platyclymenia sp. $\left(\mathrm{D}_{3}\right)$, Lytoceras lineatum Schl: $\left(\mathrm{J}_{1}\right)$, Leioceras opalinum (Reinecke) $\left(\mathrm{J}_{2}\right)$ u. a.).

Bei den niederen Nautiloiden (Lituites sp. $\left(\mathrm{O}_{2}\right)$, Trocholites depressus (Eichw.) $\left(\mathrm{O}_{2}\right)$ u. a.), bei denen sich im embryonalen Stadium nur eine Luftkammer bildet, tritt wie bei den Ammoniiten nach dem embryonalen Stadium eine ziemlich lange Periode auf, in welcher sich die niedrigen Luftkammern gestalten (Fig. 1, Kurven 2, 3; Fig. 2, Kurven 1, 2). Während dieser Periode finden auch die letzten Veränderungen des inneren Aufbaus und der äusseren Form des Gehäuses statt (Lituites sp.). Das dem Verfasser zur Verfügung stehende Material erlaubte es zwar nicht, das Auitreten des Larvenzustandes festzustellen. Interessant ist aber der Umstand, dass in dieser Gruppe sowohl Formen mit eiförmiger Gestalt der ersten Kammer vorkommen (Orthoceras, Shikhanoceras, Bactroceras, Lituites perfectus Wahl.) als auch solche, bei denen sich wahrscheinlich zwei bis drei Luftkammern während der embryonalen Entwicklung bildeten (Geisonoceras sp. 2 (S), Turoceras schnyrevae Zhuravleva $\left(\mathrm{S}_{2}-\mathrm{D}_{1}\right)$, Phragmoceras timanicum Holzapfel $\left(\mathrm{D}_{3}\right)$, Barrandeoceras tyrranum (Barr.) ( $\left.\mathrm{S}_{2}\right)$ Tarphyceras sp. $\left(\mathrm{O}_{2}\right)$ u. a.).

Bei den geraden und spiralförmigen Nautiloiden (Dolorthoceras stiliforme Shim. $\left(\mathrm{P}_{1}\right)$, Uralorthoceras tzwetaevae Shim. $\left(\mathrm{P}_{1}\right)$, Estonioceras sp. $\left(\mathrm{O}_{1}\right)$, Curtoceras teres Eichw. $\left(\mathrm{O}_{2}\right)$, Discoceras antiquissimum (Eichw.) $\left(\mathrm{O}_{3}\right)$, Metacoceras orthoconicum Ruzh. et Shim. $\left(\mathrm{P}_{1}\right)$, Rhiphaeoceras humile Ruzh. et Shim. ( $\left.\mathrm{P}_{1}\right)$, Cymatoceras sp. $(\mathrm{Cr})$, Nautilus pompilius L. u. a.), bei denen sich in der embryonalen Entwicklung ein Gehäuse von mehreren Kammern bildete, sind nach dem Verlassen des Eis keine wesentlichen Veränderungen der Gehäusestruktur zu verzeichnen, und das Wadhstum der Höhe der Luftkammern geht sofort mit der maximalen Schnelligkeit vor sich.

Aus den obigen Angaben ist zu ersehen, dass die Nautiloiden der ersten Gruppe (Lituites, Trocholites u. a.) eine Entwicklung aufweisen, die derjenigen der Ammoniiten ähnlich ist, obwohl die Mehrzahl der Vertreter dieser Gruppe keine subsphärische Kammer hat. Die Entwicklung der Nautiloiden der zweiten Gruppe (Estonioceras, Nautilus u. a.) unterscheidet sich sowohl von der Entwicklung der Ammoniiten als auch von der Entwicklung der Nautiloiden der ersten Gruppe, obgleich die äussere Form der ersten Kammer bei der Mehrzahl der Vertreter der ersten und zweiten Nautiloidengruppe die gleiche ist. Bei den abgesonderten Gruppen besteht die hauptsächliche Entwicklungsverschiedenheit darin, dass bei den Nautiloiden der ersten Gruppe die Entwicklung des Embryos im Ei nicht vollständig war, so dass ein endgültig noch nicht ausgebildetes larvenhaftes Individuum das Ei verliess und seine Entwicklung noch während der Bildung von zahlreichen (bis 70) Kammern fortsetzte; bei den Nautiloiden der zweiten Gruppe dagegen entwickelte sich das Embryo im Ei vollständig, so dass ein ausgebildetes junges Individuum das Ei verliess. 